\title{
Lead specificity of the maximum ST/heart rate slope response
}

Sir,

Once more correspondence columns have borne witness to the confusion caused by the Leeds exercise test. Yet again Professor Linden and his colleagues have been able to claim that their protocol has not been adhered to - and of course on this occasion they are correct in that respect. ${ }^{12}$ They have, however, chosen to ignore other studies that have followed their protocol meticulously and that have, nevertheless, failed to reproduce their results. ${ }^{34}$

This has surely now reached a point for real concern to be expressed. A considerable amount of time and money, much of the latter from charitable sources, has been spent trying to confirm the perfect accuracy of this test and this has proved a wild goose chase. This might be a cause for some amusement were the competition for scarce research funds not so intense. Nevertheless, the alleged usefulness of this test has been widely and uncritically accepted in many countries. There is reason to believe that the management of many patients may have been largely determined by the result of a Leeds exercise test, and of course this could well result in quite inappropriate decisions with regard to further investigation and treatment in individual cases.

The fact is that the test works only in Leeds. Nobody else, using the unmodified Leeds protocol, has been able to reproduce the results, and surely there- fore the test must now either be abandoned or else all patients undergoing it must be sent to Professor Linden's unit since that would appear to be the only place where it can be properly performed and interpreted.

It is of interest that the recent letter from Professor Linden and Dr Mary seems to indicate that the test, even in Leeds, is no longer perfect so perhaps the time has come for it to be abandoned.

Clive Layton,

London Chest Hospital,

Bonner Road,

London E2 9JX.

\section{References}

1 Beattie JM, Seibert GB, Blomqvist CG. Lead specificity of the maximum $\mathrm{ST} /$ heart rate slope response [Letter]. Br Heart f 1985; 53: 349.

2 Linden RJ, Mary DASG. Lead specificity of the maximum ST/heart rate slope response [Letter]. $\mathrm{Br}$ Heart f 1985; 53: 688.

3 Balcon R, Brooks N, Layton C. Correlation of heart rate $\mathrm{ST}$ slope and coronary angiographic findings. $\mathrm{Br}$ Heart f 1984; 52: 304-7.

4 Quyyumi AA, Raphael MJ, Wright C, Bealing L, Fox $\mathrm{KM}$. Inability of the $S T$ segment/heart rate slope to predict accurately the severity of coronary artery disease. $\mathrm{Br}$ Heart f 1984; 51: 395-8.

\section{Management of primary pulmonary hypertension}

Sir,

Dr Oakley's interesting editorial on the management of primary pulmonary hypertension $(B r$ Heart $\mathrm{f}$ $1985 ; 53: 1-4)$ contains an error. The sequence of the vascular lesions that is described ends with fibrinoid necrosis and the "plexiform arteriopathy" of Wagenvoort and Dr Oakley goes on to say "but the therapeutic dilemma is how to get hold of patients at a stage of medial hypertrophy before these irreversible changes occur." Plexiform lesions develop after fibrinoid necrosis. "Plexiform arteriopathy" does not exist. The term, plexogenic arteriopathy was devised by a World Health Organisation committee $^{1}$ to describe a morphological pattern of which the plexiform lesion is the final stage. There- fore, plexiform lesions and other irreversible changes need not to be present in plexogenic arteriopathy. The condition, at least in association with congenital heart disease, is reversible in its early stages and not only when medial hypertrophy alone is present. ${ }^{2}$ The primary form of plexogenic arteriopathy is also likely to be reversible if an effective treatment can be used at an early stage of disease.
C A Wagenvoort,
Department of Pathology,
Academisch Medisch Centrum,
Meibergdreef 9 ,
AZ Amsterdam,
The Netherlands. 